\title{
Alternaria tenuis alternata Antigen IgG4 Antibody Measurement
}

National Cancer Institute

\section{Source}

National Cancer Institute. Alternaria tenuis alternata Antigen Ig G4 Antibody

Measurement. NCl Thesaurus. Code C130153.

A measurement of the Alternaria tenuis alternata antigen IgG4 antibody in a biological specimen. 